Eixo Temático: Desenvolvimento de Estratégias Didáticas

\title{
ET-07-002 \\ TRILHA ECOLÓGICA AMBIENTAL NA PRÁTICA EDUCATIVA
}

Daffany Luana dos Santos ${ }^{1}$, Thaynara Millena de Oliveira Bezerra ${ }^{1}$, David José dos Santos ${ }^{1}$, Maria Isabel de Assis Lima ${ }^{1}$, Geryticia Ledyanne de Santana ${ }^{1}$, Daniele Andrade de Carvalho²

${ }^{1}$ Licenciando(a) do curso de Ciências Biológicas, Universidade Federal de Pernambuco (UFPE). ${ }^{2}$ Professora da rede municipal de ensino de João Pessoa, PB.

http://dx.doi.org/10.21472/congrebio2016.et-07-002

\section{RESUMO}

Um jogo didático de tabuleiro foi desenvolvido para estimular o pensamento, a criatividade e a capacidade de resolver problemas ambientais. Foi iniciado através de conversa informal, e posteriormente os alunos utilizavam o dado para saber quantas casas andar e responder as perguntas da casa em que caiam. Como futuros educadores, devemos procurar alternativas para despertar a motivação para a aprendizagem, o raciocínio lógico-educativo e o senso cooperativo, desenvolvendo a socialização. Os jogos podem ser utilizados para introduzir, amadurecer os conteúdos e preparar o aluno para o aprofundamento de itens trabalhados. Obtivemos resultados satisfatórios, pois os alunos interagiram e demonstraram maior interesse pela problemática.

Palavras-chave: Jogo didático; Ensino não formal; Educação ambiental.

\section{INTRODUÇÃO}

A educação ambiental tem enfrentado grandes desafios, como o de atrelar o discernimento dos problemas ambientais enfrentados com a prática desta consciência. Para tanto a escola tenta se ocupar de instruir os alunos, de modo que saibam desempenhar suas funções na comunidade, assim, gerando um ser consciente, e que exerça suas funções de preservar o ecossistema. Devemos considerar que pensar ecologicamente vai além dos princípios, naturalista ou moral. A garantia de um futuro depende, portanto, de uma reflexão sobre o comportamento humano diante dos recursos naturais. Uma revisão que é, em parte, tecnológica e, em grande parte, ética. É preciso buscar formas de compatibilizar o desenvolvimento tecnológico com a qualidade do meio ambiente. Este é o ponto de partida para se traçar uma unidade de propósitos e os limites da Educação Ambiental (CHAVES e FARIAS, 2005)

A temática do meio ambiente se constitui numa forma abrangente de educação, que se propõe atingir todos os cidadãos, a fim de sensibilizá-los para a conservação ecológica e deve ser trabalhada não só no ambiente escolar, mas também fora da escola. A aplicação de atividades lúdicas, como o jogo didático, é bastante pertinente em espaços não formais, no qual o ensino ocorre também de forma sistemática, mas a vivência nesses espaços pode levar a um enriquecimento no processo de ensino-aprendizagem.

Os jogos interativos para fins educacionais são considerados grandes ferramentas para ensinar, educar e transformar. O jogo estimula o aprendizado, assim, torna-se elemento gerador de conhecimento (FALKEMBACH, 2006). Destarte, realizar a prática é de fundamental importância para a formação do sujeito crítico e sensitivo de suas ações, para isso, o presente artigo propôs apresentar uma atividade realizada no Espaço Ciência que se situa entre as cidades de Recife e Olinda e atende um público com diferenças culturais, sociais e econômicas que são respeitadas e trabalhadas dentro do contexto não escolar. Apresentam exposições de alta qualidade museográfica, como planetário, auditório, anfiteatro, hall de exposições e centro 
educacional, onde estão situados laboratórios didáticos de ciências e informática, além de possuir um manguezal, ambiente para contemplação, estudos e aprendizagens.

\section{METODOLOGIA}

Esse trabalho foi desenvolvido durante a disciplina de Estágio em Ensino de Biologia 1, do curso Licenciatura em Ciências Biológicas, da Universidade Federal de Pernambuco. Inicialmente foram realizadas observações do espaço, nas quais pudemos acompanhar as atividades dos próprios monitores e notamos que o espaço ainda não continha atividades relacionadas a Ecologia, ou Educação Ambiental no ambiente externo do museu. Posteriormente, foi elaborado e aplicado um Plano de Ação Colaborativa (PAC) que, além de atender à demanda por atividades na área de Educação Ambiental, buscou incorporar a ludicidade, uma vez que percebemos, em algumas situações, a falta de interação dos alunos e a dispersão dos mesmos pelo espaço durante a explicação dos monitores. Dessa forma, propusemos a elaboração e aplicação de jogos, devido ao grande interesse da maioria por tais atividades.

Na confecção do jogo de tabuleiro utilizamos emborrachado, cola quente e cola de isopor, imagens reflexivas sobre o meio ambiente, entre outros, todos os materiais disponibilizados pelos estagiários.

Inicialmente, houve uma conversa informal com os visitantes do espaço sobre a proposta, etapas e regras do jogo. O jogo consistiu na divisão de quatro grupos, representados cada um por uma cor da coleta seletiva e cada grupo tinha o direito de jogar o dado para iniciar o jogo, um por vez (Figura 1). No decorrer da trilha cada grupo respondeu as perguntas sobre o meio ambiente que abordaram temas como desmatamento, a importância da água, poluição (ar, água, solo), aquecimento global, chuva ácida, ecossistemas e perda da biodiversidade. Os participantes de cada grupo discutiam e apresentavam suas respostas e em cada acerto os jogadores avançavam uma casa até conseguir chegar ao final da trilha.

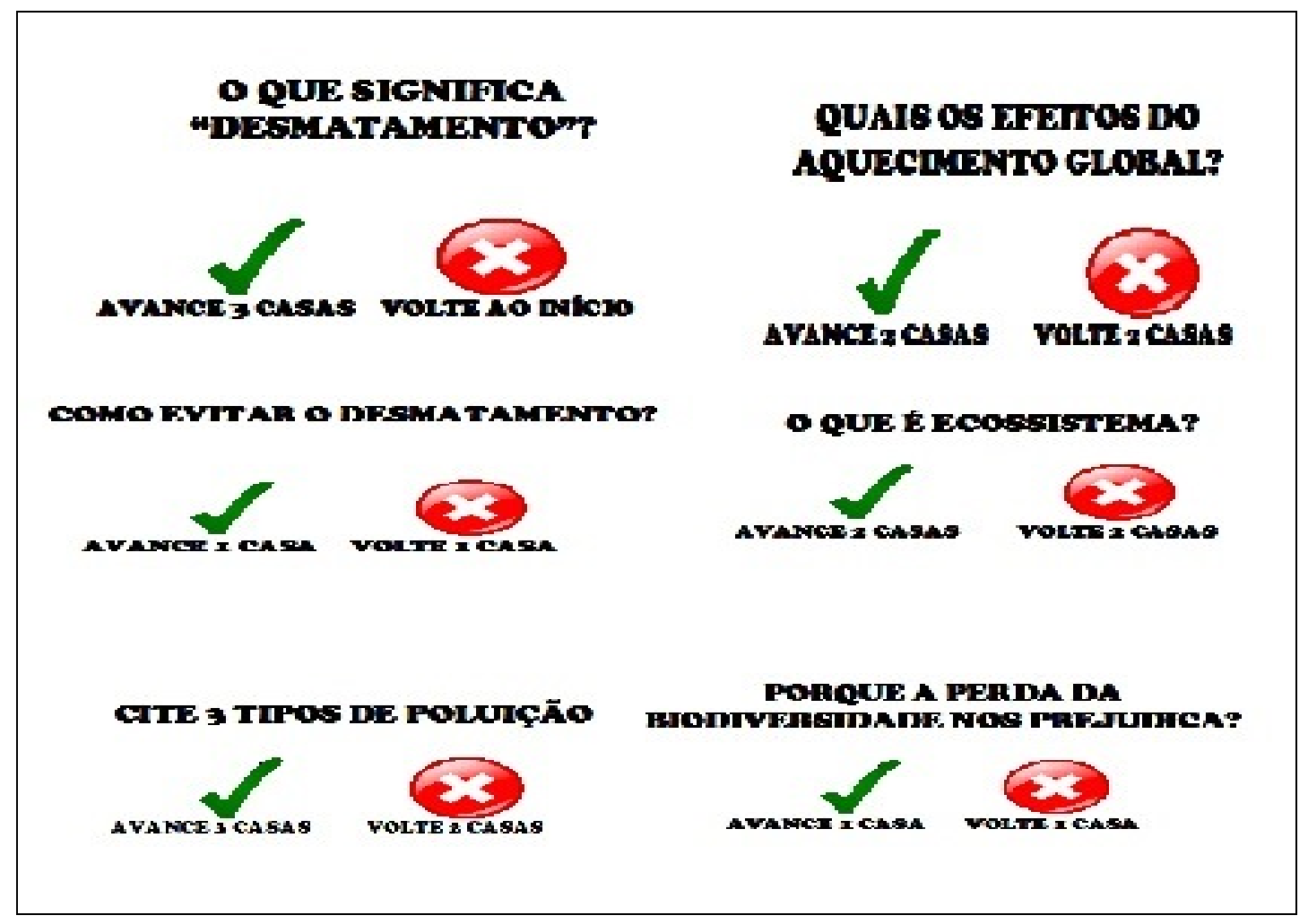

Figura 1. Modelos de perguntas abordadas no jogo de tabuleiro. 


\section{RESULTADOS E DISCUSSÃO}

A aplicação do jogo foi realizada em três dias, com carga horária de vinte horas, obtendo boas respostas em todas as turmas que participaram. Os alunos interagiram bastante entre si e durante a avaliação, após o fim do jogo, foram realizadas algumas perguntas, tais como "O que vocês aprenderam?”, "O que levaram para si”? e a satisfação foi enorme ao ouvir respostas como: "É preciso cuidar do meio ambiente!", “O meio ambiente é muito importante para nossa vida.”, “O meio ambiente precisa ser valorizado!”.

Diante disso, os resultados foram melhores que os esperados, porém é preciso realizar algumas adaptações para um melhor aperfeiçoamento do jogo, tal como aumentar o número de perguntas para evitar a repetição das mesmas e deixar o jogo ainda mais dinâmico. Também vale ressaltar que, para uma avaliação mais efetiva das atividades desenvolvidas, seria necessário analisar a aplicação dos conceitos trabalhados no cotidiano dos alunos. Por isso, há a necessidade de trabalhar a EA em espaços não formais e em sala de aula, para que a ação educativa se dê de forma mais contínua e possa ser melhor acompanhada.

\section{CONSIDERAÇÕES FINAIS}

Concluímos que o desenvolvimento do jogo que abordou temas sobre meio ambiente foi bastante satisfatório por ter contribuído para a interação dos participantes e a sensibilização dos mesmos a respeito da temática. Ainda, como sugestões para melhoria do trabalho e autoavaliação da nossa experiência com o ensino, entendemos que se faz necessário um maior embasamento teórico e compreensão sobre as vantagens e desvantagens de se trabalhar em espaços não formais, além do uso da criatividade e ludicidade para esse tipo de educação.

\section{REFERÊNCIAS}

CHAVES, A. L.; FARIAS, M. L. Meio Ambiente, escola e a formação dos professores. Ciência \& Educação, v. 11, n. 1, p. 63-71, 2005.

FALKEMBACH, G. A. M. O lúdico e os jogos educacionais. CINTED - Centro interdisciplinar de Novas Tecnologias na Educação. UFRGS, 2005. 